\title{
Medicalising the moral: the case of depression as revealed in internet blogs
}

\begin{abstract}
Depression is regularly declared to be equivalent to a bodily illness, yet critics have long contested this 'medical' view of mental disorders. Following the ideas of Szasz and Foucault, we describe an alternative 'moral' view of depression, which emphasises the agency of the individual, and presents depression as a potentially problematic but meaningful response that can be regarded as an aspect of character. We use popular internet blogs by people with depression to explore these contrasting conceptions, which can also be found in other research and information on depression. In blogs, the medical view was used to challenge what bloggers perceive as a persistently influential moral view, by deflecting criticism and responsibility, and disowning unwanted aspects of the self. At the same time, bloggers make positive use of the moral concept of depression when discussing recovery. The moral view enables people to take active steps to address their difficulties and to integrate the experience of depression into their understanding of themselves in a challenging yet rewarding process of personal development. We suggest the moral view of depression represents an enduring aspect of our understanding of ourselves, which the medical view has been superimposed onto, but has not managed to suppress.
\end{abstract}

\section{Introduction}

Depression is a common complaint, with a recent survey finding that $19 \%$ of adults in England have been diagnosed with it at some point (Health and Social Care Information Centre, 2015). Thirteen per cent of the population of England are prescribed antidepressants (Duncan, 2018) and the number of prescriptions has almost doubled in the last decade (Association, 2018).

Yet, despite its prevalence, there is no consensus about how depression should be conceived. Information produced by official organisations suggests it is a form of mental illness that is essentially equivalent to physical illness. The idea that depression is part of an individual's character, with moral implications, is regarded as an old-fashioned and discredited point of view that has been replaced by a modern, scientific understanding. Yet mental illness has long been a contested concept, with critics suggesting that it is used to conceal moral 
evaluations of certain forms of unwanted or socially inconvenient behaviour (Szasz, 1970). The contrasting views of the nature of depression are also striking features of popular internet blogs written by depression sufferers. In these blogs, people utilise the medical explanation of depression to challenge a 'moral' understanding that they perceive as extant both in their personal experience and in society at large. Despite this, bloggers themselves utilise a 'moral' framework, especially in describing their efforts to achieve 'recovery'.

The current paper sets out to articulate what we have called the 'moral' view of depression that emerges from the critique of medical conceptions of what we refer to as 'mental illness', put forward in its clearest form by the critic of psychiatry, Thomas Szasz. We call it the 'moral' view following the language used in blogs and in official information. Although there are many alternative perspectives on depression, the full implications of rejecting the medical model of depression, specifically, have not been thoroughly explored. We use empirical material to illustrate the conflicting nature of the moral and medical views of depression, and to explore reasons for the acceptance of the medical view, and for the continued survival of the moral view. We propose that the tenacity of the moral view conveys an important insight into the nature of our implicit understanding of human emotion and behaviour.

\section{The moral view of depression}

There are many critiques of the medical model of mental disorder and distress, with psychologists pointing to the inappropriate medicalisation of meaningful responses to trauma and adversity (Johnstone, 2018; Longden \& Read, 2016) and sociologists highlighting the various social influences and interests that drive and shape the medicalisation of social problems (Conrad, 2009; Gonzalez-Moreno, Saborido, \& Teira, 2015; Pilgrim, 2019; Shaw \& Woodward, 2017). Thomas Szasz was one of the first people to suggest that what we refer to as mental illness or disorder is incompatible with a medical explanation. Szasz's critique of the medical model sets it against the alternative view of people as moral agents, and points to the social and political consequences of denying this by construing behaviour as a manifestation of disease. It is worth returning to Szasz's work, therefore, to clarify what is meant by the 'moral' view of depression and to outline some of the consequences of this position. 
Szasz famously criticised the concept of mental illness for extending the biologically-rooted concept of disease to cover situations that consist of certain forms of unwanted behaviour. Human behaviour, he pointed out, is entwined with our notions of agency and moral responsibility, and cannot therefore be equated with an impersonal state such as a bodily disease. The idea of mental illness is misleading since the mind, or the mental, cannot be distinguished from the person as a whole, who is a moral agent who makes moral choices. For Szasz, mental life and mental capacities are expressed by 'the sum total of what a person does and says' (Szasz, 1996) (P 19), which can also be referred to as 'character'. Concepts such as mental illness wrongly suggest it is possible to make a distinction between an individual and her mind or behaviour.

Szasz suggests that 'human relations are inherently fraught with difficulties' (Szasz, 1960)(P 117). People can behave in ways that they, or other people, find troubling, burdensome, inconvenient or frightening. When behaviour is extreme and intended to harm, it may fall foul of the criminal law, but behaviour may be bothersome without reaching such a threshold. What we refer to as 'mental illness,' Szasz proposes, is a label applied to 'patterns of conduct unwanted by self or others' (Szasz, 2000) or 'personal conduct [that] violates certain ethical, political and social norms' (Szasz, 1970)(P 23). Modern society seeks solutions to certain inconvenient and unwanted situations by transforming them into seemingly objective, medical problems, a process that disguises the complex moral judgements being made. As Szasz put it: "mental illness is a myth whose function is to disguise and thus render more palatable the bitter pill of conflict in human relations' (Szasz, 1960)(P 118).

Szasz is often criticised for an excessive emphasis on individual responsibility and for ignoring or downplaying the social determinants of behaviour. In contrast, the French philosopher Michel Foucault analyses the rise of psychiatry within its historical context, highlighting how changes in conceptions of madness reflect broader ideological fluctuations which in turn reflect transformations in social and economic conditions. For Foucault the medical model is the end point of a specific historical trajectory concerning the social control of unproductive and disruptive behaviour. In line with Szasz, though, Foucault highlights how designating something as mental illness amounts to a negative judgement about a form of behaviour.

Foucault suggests that the modern system for the care and treatment of the mentally disordered originates in the problematisation of economic dependency that is created by the 
capitalist industrial revolution. Non-engagement in work, for whatever reason, is deemed to be deviant and in need of rectification. When the mad start to be identified as a special case, medical explanations develop and are superimposed onto the prior moral enterprise of correcting those who are mal-adjusted to the new economic system. Hence Foucault claims 'psychiatry is a moral enterprise overlaid by the myths of positivism' (Foucault, 1965) (P 276). Therefore, like Szasz, Foucault suggests that the medical approach to mental disorder obscures a deeper moral and political project aimed at managing socially undesirable behaviour. Through his historico-political analysis, Foucault shows how the medical view helps disguise a pre-existing moral framework.

Following the ideas of Szasz, people with depression should be regarded as moral agents. The situations we refer to as 'depression', are not fundamentally different from other forms of voluntary human behaviour, through which our thoughts and moods are conveyed (as opposed to involuntary 'behaviour' that is produced by a physical mechanism such as a twitch, or an epileptic fit). Therefore, people are as morally responsible for depressed behaviour as for all other behaviour. Since protracted or repeated behaviour determines what we think of as an individual's character, depression can be thought of as an aspect of character, or, in other words, as part of what constitutes the self.

By aligning depression with other behaviour, the moral view also emphasises that depression needs to be understood as a meaningful reaction to the present and past circumstances of an individual's life. Many critics of the biomedical approach, including psychiatrists R.D. Laing and Adolf Meyer, have highlighted the meaningful nature of mental illness, even its more extreme forms such as psychosis or schizophrenia (Laing, 1965; Meyer, 1948). Writers on depression note that by ascribing agency to the depressed person, the moral view can highlight the possibility of understanding and changing depressed behaviour. This may involve a process of re-evaluating the nature of one's circumstances and priorities in 'a potentially creative encounter with troubled relationships, activities, values and self-respect' (Martin, 1999) (P 271).

Although the moral view is often presented in a negative light, (by bloggers in this paper and in official information), reference to the 'moral' does not necessarily imply a negative judgement. Philosophers suggest that moral responsibility should be regarded as a set of capacities that render one 'an apt candidate for moral judgements and ascriptions of moral properties' (Fischer, 2006) (P33). Moral judgement (praise or blame, for example) is only 
valid in the presence of such capacities, but it also depends on the particular context, including prevailing social mores and norms, as well as the individual's history and circumstances. In other words, when an individual's behaviour is explicable as a reaction to a difficult situation, they are often 'excused' from blame. By highlighting the meaningful nature of behaviour, the moral view can also be seen as a pre-requisite for both the 'psychological' approach that views depression as a problematic but understandable individual response to adverse circumstances (Johnstone, 2018), and social constructionist, political and feminist positions that present depression as a manifestation of structural injustice and unequal power relations (S. Fullagar \& O'Brien, 2014; Kokanovic et al., 2013; McLeod, 2017).

Szasz and Foucault both suggest that medical concepts of 'mental illness' disguise moral and political judgements about the limits of acceptable behaviour. As highlighted by sociologists who address the nature and consequences of 'medicalisation,' this is what enables medical systems to act as forms of 'social control' (Conrad, 2009; Correira, 2017). When behaviour is considered to be a mere aberration of biology, it does not have to be understood, only corrected or effaced. Hence, the medical approach can itself be seen as a political or moral orientation, since it reinforces the values that underpin society, and presents current mores as universal, natural and timeless. As author Gary Greenberg points out:

'When doctors turn suffering into symptom, symptom into disease and disease into a condition to be cured, they are acting not only as scientists but also as moral philosophers. To claim that an affliction ought to be eradicated is also to claim that it is inimical to the life we ought to be leading' (Greenberg, 2010) (P 36).

In contrast, by suggesting that depression is an understandable, if possibly unwanted, reaction to particular life circumstances, the moral view challenges the assumption that everyone should be happy and fulfilled in contemporary society; that a life of hard work and selfsacrifice, such as embodied in Calvinist-inspired, capitalist values, brings its own rewards. In this way, a moral understanding of depressed behaviour questions the universality of modern social values and raises questions about the sort of world we live in.

The 'moral' view of depression can therefore be summarised as having the following components: 
Depression is a meaningful response to social and personal adversity that is not distinct from 'normal' emotions and their behavioural expression.

Depression may evolve into inconvenient and unwanted patterns of behaviour, which fail to conform to current social expectations and demands.

To the extent that all our feelings and behaviours contribute to make us who we are, depression may come to be regarded as a feature of the individual's character.

Individuals with depression are morally responsible for their behaviour, though this does not equate to negative moral judgement.

\section{The medical versus the moral in official information}

The modern view of depression as a common medical illness started to emerge in the 1960s alongside the marketing of antidepressant drugs (Healy, 1997; Moncrieff, 2008). This view holds that depression is a pathological condition caused by particular biological abnormalities. Although no such abnormalities have been demonstrated, hypotheses suggest that they may reside in certain neurochemical systems such as those involving noradrenalin or serotonin. Antidepressants are presented as specific treatments that act on the underlying physical mechanism of depression, and are sometimes suggested to work by reversing underlying imbalances in serotonin or other brain chemicals. These claims are not uncontested, however, with commentators pointing to the lack of evidence for any of the neurochemical theories of depression and challenging the idea that antidepressants have specific or clinically useful effects in depression (Healy, 2015; Kirsch, 2010; Moncrieff \& Cohen, 2006).

Despite the lack of confirmatory evidence, literature produced by official organisations presents depression firmly as a medical condition or disease. At the same time, it uses this idea to challenge and contest what is presented as a prior, common-sense moral understanding of depression. The National Health Service website, for example, tells us:

'Some people think depression is trivial and not a genuine health condition. They're wrong - it is a real illness with real symptoms. Depression isn't a sign of weakness or something you can "snap out of" by "pulling yourself together"'(www.nhs.uk, 2018). 
This description challenges the idea that depression is a normal human response to difficult situations and denies that the depressed person is a moral agent or that people may be able to exercise some control over their feelings and behaviours. It also equates a non-medical understanding of depression with harsh moral judgement. The NIMH also emphasises that 'most people who experience depression need treatment to get better' (National Institute of Mental Health, 2018), again implicitly contesting the claim that people may recover from depression by their own efforts.

Robert Sapolsky, Professor of Neurology at Stanford University, acknowledges in an interview with US News in 2017 how the moral point of view continues to be influential. He reprimands the public for holding such ideas, demonstrating their intuitive appeal, and illustrating the urgency with which proponents of the medical model feel they must subjugate such views:

'For far too many people suffering from major depression, or anxiety disorders or PTSD, it doesn't count as a disease in their head, and thus it's something approaching being some sort of Calvinist moral failing, something that someone should be able to overcome with some gumption and resolve - something which, if you're paralyzed by it, instead means that you're weak and self-indulgent. It's incredibly important that people realize that it is a biological disorder. It's enormously harmful not recognizing it for being the disease that it is' (Levine, 2017).

\section{Research on understandings of depression}

Numerous qualitative studies with people who have suffered from depression have also identified varied and often conflicting understandings of depression. Much of this work reveals an underlying moral notion of depression that people hold before they encounter health services and start to be initiated into the medical approach. Participants across studies described how they thought of themselves in terms of failing to cope or live up to expectations, and how they feared the negative judgement of others (S. O. B. Fullagar, W. , 2018; O'Brien, 2008; Smardon, 2008). Qualitative studies also document how people come to accept the medical view of depression as problems become more severe and entrenched (S. 
Fullagar \& O'Brien, 2013; Rogers, May, \& Oliver, 2001; Smardon, 2008), but, nevertheless, often remain ambivalent or conflicted about aspects of medical explanations and treatments (Barr \& Rose, 2008; Kokanovic et al., 2013; Smardon, 2008). When it comes to recovery, individuals frequently express non-medical understandings of depression that emphasise agency and the possibility for personal change (S. Fullagar, 2009; S. Fullagar \& O'Brien, 2013).

Qualitative research has also identified contrasting views on the meaning of antidepressant medication. Antidepressants provide a powerful symbol of the medical notion of depression, that in turn can help provide certainty and stability (McLeod, 2014). While it seems that some people accept the medical hypothesis that antidepressants can help to normalise an underlying biological malfunction, others remain uneasy about relying on drugs, and fear a loss of their agency or authenticity (Barr \& Rose, 2008; Malpass et al., 2009; McLeod, 2014; Stevenson \& Knudsen, 2008).

The social and economic determinants of depression have also been explored, including how these can play out in people's lives. Feminist writers, in particular, analyse the relationship between the expectations placed on women by modern society, to be selfless caregivers or superwomen, for example, and the experiences of depression and recovery (S. Fullagar \& O'Brien, 2014; Kokanovic et al., 2013; Lafrance, 2006). They show how depressed women often judge themselves as having failed to fulfil social expectations, yet also how they start to resist expectations and adjust their values and priorities during the process of recovery ( $\mathrm{S}$. Fullagar \& O'Brien, 2014). Ideas that stress the relationships, networks and 'assemblages' in which agential capacities take place have started to be articulated. Instead of looking within the individual to explain depression, these focus attention on the social, economic, relational and geographical contexts in which people both become depressed and strive to recover (S. O. B. Fullagar, W. , 2018; McLeod, 2014).

Although none set out a moral view of depression, as such, qualitative researchers identify the 'tensions between different epistemological assumptions' (S. Fullagar \& O'Brien, 2014) (P 116). Fullagar and O'Brien (2014) stress the difference between explanations that highlight individual deficits on the one hand, including typical medical ideas about depression, and cognitive and behavioural models that focus on the individual as the site of the problem, and 'social determinants, personal recovery and self-responsibility' on the other (P 116). Other researchers refer to diagnosis and the illness model as a double-edged sword, 
describing how it can provide a consoling explanation for 'a history of difficulties and failures' on the one hand, yet also be 'enfeebling' in its denial of agency (Karp, 1994)(P 23).

Surveys of the general public's beliefs about the nature of depression also indicate that 'moral' views persist despite concerted campaigns to present depression in a medical light. Surveys conducted in the $21^{\text {st }}$ century in the United States, Australia, Italy and Germany indicate that between $20 \%$ and $55 \%$ of the public see depression as an expression of 'weakness of character' or some similar concept (Blumner \& Marcus, 2009; Dietrich, Mergl, Freudenberg, Althaus, \& Hegerl, 2010; Munizza et al., 2013; Pilkington, Reavley, \& Jorm, 2013), even though, when asked directly, the vast majority of respondents (88\%) now also endorse the view that depression is caused by a chemical imbalance (Pilkington et al., 2013). The public are also somewhat reluctant to accept that antidepressants or other specifically medical interventions are the most appropriate treatment for depression, with only a third to two thirds of respondents believing that these are effective or important (Blumner \& Marcus, 2009; Dietrich et al., 2010; Munizza et al., 2013).

A review of patient surveys found thatpeople with depression are more likely to endorse a psychological model of depression as a meaningful response to adverse circumstances than a biological one (Prins, Verhaak, Bensing, \& van der Meer, 2008). In some surveys, respondents mention personality characteristics and their own behaviour as contributing to depression (Brown et al., 2007; Hansson, Chotai, \& Bodlund, 2010). Most surveys find that the majority of people diagnosed with depression prefer psychological therapy to antidepressants or other biological treatments (Prins et al., 2008; van Schaik et al., 2004).

Official literature, qualitative research and population surveys all concur, therefore, in identifying what can be termed a moral view of depression which challenges and conflicts with the medical view.

\section{Depression blogs}

The following material is taken from an analysis of internet blogs written by people who identify themselves as having depression. Research on the internet is becoming more important as social interaction on the internet increases. The internet is a major arena for the articulation of discourses and debate, in particular around issues of health and illness (Hookway, 2008; Lupton, 2014). Blogs have the additional advantage of being spontaneously 
produced, and not influenced by the requirements of research settings, or researcher's questions. These personal accounts are usually reflexive and introspective exercises, and can be viewed as a detailed example of the dynamic process of the construction of an illness narrative. This refers to a narrative in which a person comes up with ways of understanding and explaining their illness, including its aetiology and place in the story of their life(Kangas, 2001).

In order to identify the blogs most likely to be read by other people, and hence to be influential, we selected the first ten blogs, with more than 20 posts that appeared in four out of five Google searches carried out between the 13th May and the 15th September 2016. The search terms used were "depression blog" after trialling different variations and combinations of these words, these words in this order were selected because they returned the most hits.

Current advice on using material from the internet is to consider ethical issues on a study by study basis (Denscombe, 2014; British Psychological Society, 2013). Guided by an 'Ethics of Care' approach (McKee \& Porter, 2009) and previous research using blogs (Brownlow \& O’Dell, 2002; Clarke \& van Amerom, 2008; Kotliar, 2016), the strategy developed for the current study involved the use of blogs that were accessible without a password, based on the justification that these blogs are in the public domain. As an insurance, bloggers were also contacted personally and all gave their consent for their material to be used in the research. Ethics permission was not sought, as it was not usual for research involving material in the public domain at the time the research was initiated, but nevertheless, the research followed University College London's ethics committee guidance delivered subsequently for similar projects. Hence bloggers were assigned a number for use in the text, and all reference to them was anonymised, and demographic characteristics are only provided for the group as a whole. Minor details within presented quotations are altered to preserve bloggers' anonymity.

A thematic analysis of the blogs was conducted, using a hermeneutic approach, proposed by Stepnisky (Stepnisky, 2007) and based on Taylor (Taylor, 1989), in which human life is conceived of as an interpretive enterprise, and attention is given to the language and symbols of interpretation, while remaining grounded in everyday realities. For this, introspective, interpretive narratives of illness are a rich source of data. We present some key themes that emerged from our analysis that illustrate the arguments put forward above. 


\section{Characteristics of bloggers}

Seven bloggers were women and three were men. Seven lived in the US, two in Canada and the origin of the other was not given. The youngest blogger was in his 20s, and the three eldest (among the seven who revealed their age) were in their 50s. Seven were in employment. Bloggers had been diagnosed with depression for between one year and 'decades,' and they had been blogging for one to 12 years. One blog contained over 100 posts, and the others ranged from 31 to 91 posts. All bloggers had taken antidepressants at some stage. Seven were still taking them and three had stopped.

\section{Presentations of depression in blogs}

A key feature of all the blogs was the co-existence of both the medical and moral understandings of depression. Bloggers presented the standard medical view of depression as a brain-based disorder equivalent to other medical conditions, and most of them affirmed the importance of antidepressant treatment as a means of overcoming depression. As with official information, the medical view was often presented in order to contest and oppose a moral view of depression, the latter being present, implicitly or explicitly, in all the blogs. Some bloggers reported their internal struggles to suppress their own moral understanding of their situation; others were challenging views they regarded as prevalent within the community in general, or among friends or colleagues. Many bloggers used the medical view to separate themselves from their depression. On the other hand, all bloggers described their recovery in moral terms. Recovery was presented as a process of intentional change in how people perceived the world and lived their lives- a process that could be conceived as a deliberate attempt to change their character. Thus, in both what they denied and what they embraced, bloggers revealed an enduring, underlying moral understanding of the nature of depression.

\section{The medical view of depression}

In line with other qualitative research (Barr \& Rose, 2008; McLeod, 2014; O'Brien, 2008; Rogers et al., 2001) all bloggers expressed some form of biological explanation of depression, and most reproduced the typical medical view. Bloggers referred to depression as an 'illness' or a 'biological brain disease' (B02) and often cited the idea that it was the result 
of a brain chemical imbalance. One blogger described how she thought that people with depression do not have enough "“happy” chemicals' in the brain (B01).

The idea that depression is equivalent to familiar bodily diseases is repeatedly stressed in order to demonstrate the distinctiveness and severity of the individual's situation, and the need for medical treatment. One blogger compared depression to having a brain tumour and elsewhere he explains that he needs medical care for his depression just as he would if he had an appendicitis or diabetes (B02).

Receiving medical treatment is closely connected with the idea of depression and other mental disorders being discrete medical conditions that have a biological cause.

Antidepressants, for example, are described as specific agents that 'lift' or 'normalise' depression and return the individual to a state of 'health' (B06; B08). The idea that there is a delicate balance between medication and depression-inducing brain chemicals that requires precisely the right dose and type of drug is expressed by one blogger who describes the long process of finally finding the right dose to 'normalise' her mood (B06).

As McLeod (2014) found in her qualitative study, medication symbolises the validation of suffering through representing the medical view. This was also evident in the blogs. Through the prescription of medication, intangible internal distress is rendered objective and visible: medication becomes the currency of distress, with bloggers explaining how medications need to be increased to reflect the severity of their symptoms (B02). One blogger protests that people did not believe she had depression because she was not taking medication (B04). Without medication, the medical status of her situation, and its associated legitimacy, remains precarious.

\section{Countering the moral view of depression}

\section{a) Failure and responsibility}

As in official information, the medicalised understanding of depression was often invoked by bloggers to counteract the moral view of depression as a state of worthlessness that sufferers could be held responsible for. Thus the medical and moral views of depression are frequently juxtaposed in sections that discuss the nature of depression. One blogger describes how she thought of herself as a 'failure,' a bad mother and a 'horrible person' until she realised that 
she had an illness; an illness that can affect anyone, even the 'loveliest people' (B09). This view of the blogger as an unworthy person follows directly from the idea that she is responsible for her own behaviour. The medical notion that depression is a disease challenges this view because of the general acceptance that illness and disease are bodily processes that are not amenable to voluntary control. In fact, another blogger explicitly describes how depression is beyond a person's control because it is a 'medical condition' (B07).

Another blogger, who works in a company in a professional capacity uses the medical view of depression in a similar manner to counter the charge that depressed people are 'lazy or inept'. She thinks that many people do not consider depression to be an illness, and think of it as an 'excuse' to avoid having to work too hard (B06). She also describes how people with depression can harbour the same thoughts, blaming themselves for being 'incompetent' and lacking the motivation to fulfil the demands of their job. They castigate themselves for their lack of success. Instead of taking responsibility and blaming themselves, she urges that they should recognise that they are not work-shy, they are 'sick'.

Countering the idea that individuals are responsible for their behaviour when depressed is important to the bloggers because it helps to reduce their own feelings of shame and deflect blame. Several bloggers assert that depression is not 'anyone's fault' and not something to be 'ashamed of' (B05) Comparisons with medical conditions are used to reinforce this point of view, with bloggers suggesting that having depression is no more the fault of the sufferer than is cancer or multiple sclerosis (B02).

Along with medical language, capitalisation and specific diagnostic codes are sometimes employed to emphasise the objective, medical nature of depression, and the blamelessness of the sufferer. One blogger describes how he has 'Major Depression, Recurrent and Severe without Psychotic Features' and cites the precise diagnostic code number. This is used to stress that depression is a brain illness that is not his responsibility: 'It is an illness of my brain...That doesn't mean I'm at fault' (B02).

The insistence of such writing suggests bloggers feel that the view of depression as a moral failing is still widely endorsed and influential. Indeed, it creates the impression that they are arguing with themselves, trying to rationalise away deeply embedded and intuitive inclinations. Some bloggers articulate this internal battle with their own moral sense of depression, describing how they must subdue this view and replace it with the medical view 
that depression is a disease. Blogger 2 describes how he 'beats' himself 'up' for not being able to overcome the symptoms of depression, even though he knows it is a biological brain condition. He cannot help himself from making it a 'moral issue' and feeling that it is a negative judgement on his character, despite the fact that he 'knows' it is an illness and hence it is nothing to do with his character.

\section{b) Depression and the self: It's not me, it's my depression}

The function of the medical view of depression is most graphically illustrated by the way in which it facilitates a separation between the self and depressed behaviour. The medical view deflects blame and shame from the sufferer by locating the source of the unwanted feelings in a biological process that is independent of the intentions, desires and conscious behaviour of the individual. The concept of depression as an illness is therefore directly opposed to the notion of depression as a feature of a person's character or personality, often referred to as a 'character flaw'. Among many examples, blogger 5 asserts that 'Depression and anxiety are genuine illnesses - not character flaws' (B05). The opposition of 'illness' to 'character' enables bloggers to manage their identity or self-image. Behaviour that might otherwise be a source of shame or guilt can be externalised, disassociated from the self and attributed to the illness. In this respect the blogs are reminiscent of Stepnisky's (2007) study of people's attitudes to antidepressant treatment, which highlights how the medical understanding of depression that is embodied in the taking of antidepressants can produce a separation between the self and its problems.

A common rhetorical device used to emphasise the separation between depression and the self was personification, often with depression depicted as a predator or a thief. One blogger describes depression as feeling like a 'thing' that was always ready and waiting to 'pounce' (B02). Another describes depression as an active entity that 'steals away' the person (B10). Depression has a life of its own, it is external and malicious, like the 'devil' (B06) or a 'demon' (B02). It is sometimes portrayed as the opponent in a fight that needs to be actively resisted and 'defeated' by the self (B02).

Crediting depression with human-like agency enables the sufferer to locate responsibility for past events in the depression, rather than the self. Thus, one blogger describes how 
depression destroyed his life like a 'wrecking ball', causing him to lose his spouse, his job, his house, precipitating him into alcohol misuse and leaving him unable to care for himself (B02).

The location of depression in the brain results in a further separation of the brain from the self, with bloggers identifying their depressed thoughts as coming from their brains, rather than themselves. One blogger says: 'I am a worthless piece of crap. My brain tells me that' (B08). In this way, agency is transferred from the self to the brain, with the brain represented as acting to undermine the real self. Another blogger describes how his brain lets dark and paranoid thoughts 'seep out' at times when he is depressed (B02).

The personification of depression employed in many blogs combined with the language of combat and effort, might reflect the difficulty bloggers had in effecting the separation they desired between themselves and their depression. It seems a more entangled view of the relation between the self and its moods lurked behind these descriptions that was not easily dislodged. One blogger expressed this difficulty directly:

'Sometimes it is difficult to separate myself from my mental illness...I forget where the mental disorder ends and where I begin' (B03).

\section{Embracing the moral}

\section{a) Recovery is in our hands}

Despite presenting the typical medical view of depression as a neurochemical condition that was separate from the self, the moral concept of depression was woven into bloggers' understanding of their situation, especially in regard to the process of recovery. All bloggers presented recovery as a process of personal change and development that was the responsibility of the sufferer, consistent with the idea of depression as an aspect of character.

When describing the process of recovery, bloggers make statements about how individuals are ultimately in 'control' of their 'mental health' (B04), that it is their responsibility to get better and that trying to recover is a choice that people can make (B06). These sentiments contradict those expressed elsewhere in the blogs, reflecting the ambivalence identified in 
other research (Barr \& Rose, 2008; S. Fullagar \& O'Brien, 2014; Rogers et al., 2001). The same individuals characterise depression as a biological condition that is independent of the individual it affects in one section of a blog, but in another refer to recovery as a personallydriven, active process that requires hard work, determination and 'willpower' (B04) on the part of that individual.

One blogger recognises the tension implied by the moral view of recovery:

[It is] 'both a blessing and a misfortune that we diagnosed with mental illness hold our recovery in our own hands. It provides fuel for both endless freedom and endless self-blame. We are both the imprisoned and the guard with the key ring. If only I could stop dropping the keys' (B01).

In some blogs, biological and moral explanations are intermingled in the idea that the individual's actions are necessary to counteract the biological process or 'chemical warfare' that is unfolding in the brain (B04). One blogger describes the mental effort required to prevent the depressed thoughts, and the 'stories' produced by the neurochemical processes that constitute depression, from taking over, but she emphasises that relinquishing one's self to such thoughts is avoidable; she can resist it (B06).

\section{b) A new 'me'}

Fullagar \& O'Brien speak of recovery from depression as involving a process of personal transformation involving changes in lifestyle, activities and resistance to social expectations (S. Fullagar, 2009; S. Fullagar \& O'Brien, 2013, 2014). Bloggers also describe how recovery from depression involves a purposive effort to change their outlook and priorities, in other words, to change their character. Absence of depression, the aim of a medical approach, is not the bloggers' sole aim. True recovery, according to this view, involves an internal change; developing a new orientation to life with new meanings and new values. In this way, recovery from depression is different from recovery from a physical condition. Although the latter can also involve a profound process of insight and adjustment, in the case of depression 
the process is not simply an incidental consequence of the experience of the condition and its treatment, it is what constitutes recovery, in itself.

Two bloggers bring out this aspect of recovery most clearly. Blogger 6 describes the deliberate cultivation of gratitude as an important antidote to depression. She describes the development of this attitude as a 'choice' that is part of recognising that it is possible to take control of one's life; to take back 'the steering wheel' from depression and to experience a renewed sense of agency (B06). She links this idea with ideas about the medical nature of depression by suggesting that gratitude is not just a feeling, but is reflected in healthy activity within the brain (B06).

For this blogger, among others, the process of recovery was a personal transformation that involved calling into question the value she had formerly placed on 'success' in her career and replacing it with an entirely new way of considering what matters to her. She discusses how she has started to re-examine her previous goals and instead of asking what it takes to be successful, has started to ask what it means to lead a 'good life' (B06).

Other comments suggest this blogger views depression as an integral and valued part of one's character, which contrasts with the separation between depression and self that is achieved through the use of the medical concept. She describes how people with depression are engaged in a heroic 'battle' against adversity, and how this reflects a strength of character that is rarely acknowledged (B06).

Blogger 5 also writes proudly about having effected a change in his values and way of life, recognising that his former lifestyle was not conducive to happiness or wellbeing. $\mathrm{He}$ describes having lived a fast-paced, busy life, working hard and being 'successful'. When he lost his job due to an extended period of 'crisis,' he lost all 'sense of purpose' as this had been 'wrapped up' in his career (B05). For him, recovery involved a painful process of reevaluating his life and priorities, and developing a different attitude to work. He describes how he had to learn to be in the present and to appreciate the little things that 'make life meaningful' (B05). He describes this process as forging a 'new self', which involved a difficult and protracted but ultimately rewarding journey to find a 'new normal' (B05). 
Blogger 5 also illustrates how the process of transformation leads him to accept depression as a valued part of himself. At one point he asks whether having a mental illness makes one "'weak or weird or damaged' or whether it could 'make you stronger, more courageous and more beautiful?'. He calls on depression sufferers to embrace their mental illness as part of who they are (B05). At one point he personifies depression as a challenging companion on his life's journey, a part of himself he has had to master and by doing so has come to live more authentically.

\section{c) The meaning of depression}

In the context of writing about the personal transformation involved in recovery, many bloggers expressed a moral understanding of the nature and origins of depression, presenting depression as a meaningful response to conventional social expectations and personal circumstances.

The bloggers whose personal transformations were described in the last section both reveal a view that depression is a consequence of modern society that values material success and encourages dedication to work at the expense of the more spiritual or communal aspects of life that are essential to happiness. Blogger 6, who elsewhere emphatically presents the medical view of depression, suggests that depression is the result of a modern materialist culture, which creates the conditions that allow 'depression to develop' (B06). In her view, depression is an understandable reaction to the inadequacy of modern aspirations for material success. She critiques the 'myth' that money and material possessions can bring happiness and links the development of mental disorder to the 'hectic' manner of modern life, which makes managing stress 'very difficult' (B06).

Blogger 5 also identifies how unrealistic expectations of what he should achieve at work had contributed to his problems. He describes how he had felt compelled to live up to an 'image of perfection.' Getting better has involved changing his priorities in order to 'take care' of himself, and this has involved developing a new attitude towards work which enables him to relinquish his prior expectations (B05). 
Bloggers 5 and 6 illustrate how regarding depression as a meaningful reaction to the circumstances of modern life raises questions about the universal appeal of norms, such as beliefs in the merit of hard work and material success.

Bloggers also present accounts of depression as personal reactions to adverse, or traumatic life events, and as part of the interaction between past experiences and character. As well as suffering from the pressure of unrealistic expectations, blogger 5 writes of having to learn new ways to cope with years of past 'pain' (B05). Blogger 8 describes his depression as a form of unresolved grief at the death of his parents, which he attempted to manage by throwing himself into work and activity, but which 'festered' inside him, expressing itself 'sideways' in 'anger, denial and desperation' (B08). This blogger also acknowledges depression as an aspect of his character that he has to learn to master or overcome, although medical concepts are integrated into the account:

'I sit on my pot of self-pity ... I get jealous and mad and jealous and sad and jealous and angry and depressed. I do this to myself. I allow this brain chemistry to happen. I allow myself to have stupid, unrealistic expectations' (B08).

The statement clearly indicates a moral view of depression as a condition the individual should be able to resist. The medical language of brain chemistry is added perhaps to provide authority, or to demonstrate that the blogger is familiar with official views about depression, but it does not detract from the impression that the blogger considers depression to be a result of his own inclinations to think and behave in certain ways.

Blogger 6, too, at one point describes depression as a state of being 'stuck' in the past, unable to move on with life. Overcoming depression is achieved by sifting through one's past in order to understand what led up to the state of depression and what perpetuates it. Here, depression is depicted as an unhelpful attitude of mind that can be overcome with intentional, individual effort.

\section{Discussion}


The material from depression blogs reveals the presence of a moral concept of depression, which, in line with the ideas of Thomas Szasz, regards sufferers as moral agents who are responsible for their behaviour and who can take active steps to facilitate their own recovery. This is contrasted with a co-existing but contradictory medical view of depression. The medical view presents depression as a disease, originating in the body and distinct from the individual's character or self. The moral view presents it as a situation consisting of unwanted patterns of feelings and behaviour that, like all other feelings and behaviour are associated with character and which can be altered by a laborious, but rewarding process of personal change.

Despite campaigns to promote a medical understanding of depression, the moral view seemed to be deeply ingrained in bloggers' thinking. They could not simply present themselves as having a disease, as they would if they were sufferers of diabetes or heart disease. They needed to challenge the moral view explicitly and assertively, even sometimes to themselves. In this way, they echoed official descriptions of depression, which also overtly disavow the moral view, thereby confirming its continued influence. Indeed, as one blogger commented: 'there is substantial media coverage about depression being an illness, but most people do not believe it' (B06). In this way, the moral view appears to represent a deep-seated or 'commonsense' attitude towards the experience of depression, onto which, as Foucault suggested, the medical view has been imposed.

Previous qualitative research has identified elements of the moral view outlined here. People talk of depression in terms of not coping with societal demands, for example, and express feelings of failure (S. O. B. Fullagar, W. , 2018; Smardon, 2008). The idea of depression being a catalyst for a valued process of self-transformation is also encountered (S. Fullagar, 2009; S. Fullagar \& O'Brien, 2013, 2014). Philosophical analyses of historical narratives illustrate the links between depression and a crisis of faith or values (Martin, 1999). Research on antidepressants reveals people's anxieties about how drugs might change their authentic character (Malpass et al., 2009; McLeod, 2014; Stevenson \& Knudsen, 2008). Research that reports people's acceptance of the medical view of depression, also, nevertheless, identifies considerable ambivalence about it (Barr \& Rose, 2008; S. Fullagar \& O'Brien, 2014; Rogers et al., 2001). Despite this, the nature of the moral view of depression and its implications have not been properly explicated or discussed. 
The blog material confirms previous analyses of the appeal of medicalisation (Conrad \& Potter, 2000). Since bodily diseases consist of autonomous biological processes that unfold independently of the individual's agency, characterising depression as a medical condition enabled bloggers to renounce responsibility for their actions, and associated guilt and shame. Research has also highlighted how the medical view can produce a sense of stability, which is cemented in the material presence of antidepressant tablets, but which might theoretically be achieved in some other way (McLeod, 2014).

In line with other research (S. Fullagar, 2009; S. Fullagar \& O'Brien, 2013, 2014), the moral view put forward by bloggers' emphasised the meaningful nature of depression, and the importance of personal change or transformation in the process of recovery. Thus depression was inferred to consist of inconvenient or unhelpful reactions to adverse cultural or individual circumstances, that could be improved by a process of intentional effort, often involving a reorientation of moral values and leading to a more satisfying and authentic way of life.

In this way the blogs illustrate how the moral view of depression challenges contemporary social norms and values. Some bloggers had not found fulfilment in everyday modern life, despite having all the trappings of success. The moral view therefore aligns with critiques of neoliberal capitalism that question whether modern values that prioritise occupational performance and material acquisition are, in fact, conducive to happiness (Cederstrom, 2018; Ferguson, 2007). In contrast, by locating depression within the individual's body or brain, the medical view of depression conceals the role of external influences, including the unquestioned values that structure modern life in western societies. By divorcing depression from the individual's agency, the medical view logically precludes both personal resolution and social criticism.

However, the moral view with its emphasis on agency also entails that an individual is potentially open to moral judgement from others and from themselves. Karp (1994) describes the double edge sword of the medical position- the moral position also has two facets. While it enables people through its emphasis on the possibility of change, it also renders people susceptible to accusations of bad behaviour or weakness of character. This is likely the reason why other analysts have shied away from presenting the moral view of depression as a cogent position. Yet, as Foucault (1965) suggested, these moral judgements can be embedded in medical concepts too, not-withstanding their apparent objectivity and moral neutrality. 
Having a mental illness remains a stigmatised identity, as recognised by many participants in qualitative studies (S. Fullagar \& O'Brien, 2014; Karp, 1994; Smardon, 2008). If depression is understood within a moral framework, moral judgements and the social expectations they arise from, can be challenged. Disguising these judgements in medical terminology makes them immune to question or criticism.

This article highlights the existence and persistence of a 'moral' view of depression, which is revealed both in the ways that bloggers and others reject and challenge it, as well as the ways in which they embrace and accept it. It seems that the medical view has not succeeded in banishing the moral view because the latter still makes intuitive sense to people and enables them to take effective action. In this way the blogs illustrate how, as suggested by Szasz and Foucault, the medical view of depression has been superimposed onto a more deep-seated moral orientation that continues to form the foundations of our understanding of human emotions and behaviour.

\section{References:}

Association, P. (2018, 29th March 2019). Antidepressant prescriptions in England double in a decade. The Guardian. Retrieved from https://www.theguardian.com/society/2019/mar/29/antidepressant-prescriptions-inengland-double-in-a-decade

Barr, M., \& Rose, D. (2008). The great ambivalence: factors likely to affect service user and public acceptability of the pharmacogenomics of antidepressant medication. Sociol Health Illn, 30(6), 944-958. doi:10.1111/j.1467-9566.2008.01116.x

Blumner, K. H., \& Marcus, S. C. (2009). Changing perceptions of depression: ten-year trends from the general social survey. Psychiatr Serv, 60(3), 306-312. doi:10.1176/appi.ps.60.3.30610.1176/ps.2009.60.3.306

Brown, C., Battista, D. R., Sereika, S. M., Bruehlman, R. D., Dunbar-Jacob, J., \& Thase, M. E. (2007). Primary care patients' personal illness models for depression: relationship to coping behavior and functional disability. Gen Hosp Psychiatry, 29(6), 492-500. doi:10.1016/j.genhosppsych.2007.07.007

Cederstrom, C. (2018). The happiness fantasy. Cambridge: Polity Press.

Conrad, P. (2009). Medicalization and social control. Annual Review of Sociology, 18, 209232.

Conrad, P., \& Potter, D. (2000). From hyperactive children to ADHD adults: observations on the expansion of medical categories. Social Problems, 47(4), 559-582.

Correira, T. (2017). Revisiting Medicalization: A Critique of the Assumptions of What Counts As Medical Knowledge

image. Frontiers in Sociology, 2:14. doi:doi: 10.3389/fsoc.2017.00014 
Dietrich, S., Mergl, R., Freudenberg, P., Althaus, D., \& Hegerl, U. (2010). Impact of a campaign on the public's attitudes towards depression. Health Educ Res, 25(1), 135 150. doi:10.1093/her/cyp050

Duncan, P. D., N. . (2018, 10th August 2018). Four million people in England are long-term users of antidepressants. The Guardian. Retrieved from https://www.theguardian.com/society/2018/aug/10/four-million-people-in-englandare-long-term-users-of-antidepressants

Ferguson, I. (2007). Neoliberalism, happiness and wellbeing. International Socialism, 117(117). Retrieved from https://isj.org.uk/neoliberalism-happiness-and-wellbeing/

Fischer, J. M. (2006). My Way: Essays on moral responsibility. Oxford: Oxford University Press.

Foucault, M. (1965). Madness and Civilisation. New York: Random House Inc.

Fullagar, S. (2009). Negotiating the neurochemical self: anti-depressant consumption in women's recovery from depression. Health (London), 13(4), 389-406. doi:10.1177/1363459308101809

Fullagar, S., \& O'Brien, W. (2013). Problematizing the neurochemical subject of antidepressant treatment: the limits of biomedical responses to women's emotional distress. Health (London), 17(1), 57-74. doi:10.1177/1363459312447255

Fullagar, S., \& O'Brien, W. (2014). Social recovery and the move beyond deficit models of depression: a feminist analysis of mid-life women's self-care practices. Soc Sci Med, 117, 116-124. doi:10.1016/j.socscimed.2014.07.041

Fullagar, S. O. B., W. . (2018). Rethinking women's experiences of depression and recovery as emplacement: Spatiality, care and gender relations in rural Australia. Journal of Rural Studies, 58, 12-19.

Gonzalez-Moreno, M., Saborido, C., \& Teira, D. (2015). Disease-mongering through clinical trials. Stud Hist Philos Biol Biomed Sci, 51, 11-18. doi:10.1016/j.shpsc.2015.02.007

Greenberg, G. (2010). Manufacturing depression: The secret history of a modern disease. London: Bloomsbury publishing.

Hansson, M., Chotai, J., \& Bodlund, O. (2010). Patients' beliefs about the cause of their depression. J Affect Disord, 124(1-2), 54-59. doi:10.1016/j.jad.2009.10.032

Health and Social Care Information Centre. (2015). Health Survey for England 2014. Retrieved from London: https://digital.nhs.uk/data-andinformation/publications/statistical/health-survey-for-england/health-survey-forengland-2014

Healy, D. (1997). The Antidepressant Era. New York: Harvard University Press.

Healy, D. (2015). Serotonin and depression. BMJ, 350, h1771. doi:10.1136/bmj.h1771

Hookway, N. (2008). Entering the blogosphere': some strategies for using blogs in social research. Qualitative Research, 8, 91-113.

Johnstone, L. B., M. with Cromby, J., Dillon, J., Harper, D., Kinderman, P., Longden, E., Pilgrim, D. \& Read, J. . (2018). The Power Threat Meaning Framework: Towards the identification of patterns in emotional distress, unusual experiences and troubled or troubling behaviour, as an alternative to functional psychiatric diagnosis. Leicester: British Psychological Society.

Kangas, I. (2001). Making sense of depression: Perceptions of melancholia in lay narratives. Health, 5, 76-92. doi:doi:10.1177/136345930100500104

Karp, D. A. (1994). Living with depression: illness and identity turning points. Qualitative Health Research, 4, 6-30.

Kirsch, I. (2010). The emperor's new drugs: exploding the antidepressant myth. London: Basic Books. 
Kokanovic, R., Butler, E., Halilovich, H., Palmer, V., Griffiths, F., Dowrick, C., \& Gunn, J. (2013). Maps, models, and narratives: the ways people talk about depression. Qual Health Res, 23(1), 114-125. doi:10.1177/1049732312467231

Lafrance, M. S., J. (2006). Constructing a non-depressed self: Women's accounts of recovery from depression. Feminism and Psychology, 16(3), 307-325.

Laing, R. D. (1965). The Divided Self. Pelican Books.

Levine, D. (2017). Is depression a disease? . US News(19/09/2017). Retrieved from https://health.usnews.com/health-care/patient-advice/articles/2017-09-19/isdepression-a-disease

Longden, E., \& Read, J. (2016). Social Adversity in the Etiology of Psychosis: A Review of the Evidence. Am J Psychother, 70(1), 5-33. doi:10.1176/appi.psychotherapy.2016.70.1.5

Lupton, D. (2014). Digital sociology. London: Routledge.

Malpass, A., Shaw, A., Sharp, D., Walter, F., Feder, G., Ridd, M., \& Kessler, D. (2009). "Medication career" or "moral career"? The two sides of managing antidepressants: a meta-ethnography of patients' experience of antidepressants. Soc.Sci.Med., 68(1), 154-168. Retrieved from PM:19013702

Martin, M. W. (1999). Depression: illness, insight and identity Philosophy, Psychiatry \& Psychology, 6, 271-286.

McLeod, K. (2014). The missing work of collaboration: Using assemblages to rethink antidepressant action. Contemporary Drug Problems, 41(109-142).

McLeod, K. (2017). Wellbeing machine: how health emerges from the assemblages of everyday life. Durham, NC: Carolina Academic Press.

Meyer, A. (1948). The commonsense psychiatry of Dr Adolf Meyer. New York: McGraw Hill.

Moncrieff, J. (2008). The creation of the concept of the antidepressant: an historical analysis. Social Science and Medicine, 66, 2346-2355.

Moncrieff, J., \& Cohen, D. (2006). Do antidepressants cure or create abnormal brain states? PLoS.Med., 3(7), e240. Retrieved from PM:16724872

Munizza, C., Argentero, P., Coppo, A., Tibaldi, G., Di Giannantonio, M., Picci, R. L., \& Rucci, P. (2013). Public beliefs and attitudes towards depression in Italy: a national survey. PLoS One, 8(5), e63806. doi:10.1371/journal.pone.0063806

National Institute of Mental Health. (2018). Depression: what you need to know. Retrieved from https://www.nimh.nih.gov/health/publications/depression-what-you-need-toknow/index.shtml

O'Brien, W. F., S. (2008). Rethinking the relapse cycle of depression and recovery: a qualitative investigation of women's experiences. . Social Alternatives, 27, 6-13.

Pilgrim, D. (2019). Key concepts in mental health. London: Sage Publications Ltd.

Pilkington, P. D., Reavley, N. J., \& Jorm, A. F. (2013). The Australian public's beliefs about the causes of depression: associated factors and changes over 16 years. $J$ Affect Disord, 150(2), 356-362. doi:10.1016/j.jad.2013.04.019

Prins, M. A., Verhaak, P. F., Bensing, J. M., \& van der Meer, K. (2008). Health beliefs and perceived need for mental health care of anxiety and depression--the patients' perspective explored. Clin Psychol Rev, 28(6), 1038-1058.

doi:10.1016/j.cpr.2008.02.009

Rogers, A., May, C., \& Oliver, D. (2001). Experiencing depression, experiencing the depressed: the separate worlds of patients and doctors. Journal of Mental Health, 10(3), 317-333. 
Shaw, I., \& Woodward, L. (2017). The medicalisation of unhappiness? The management of mental distress in primary care. In I. Shaw \& K. Kaupinnen (Eds.), Constructions of Health and Illness. European Perspectives. (pp. 124-136). London: Routledge.

Smardon, R. (2008). 'I'd rather not take Prozac': stigma and commodification in antidepressant consumer narratives. Health (London), 12(1), 67-86. doi:10.1177/1363459307083698

Stepnisky, J. (2007). The biomedical self: hermeneutic considerations. Social Theory and Health, 5(3), 187-207.

Stevenson, F., \& Knudsen, P. (2008). Discourses of agency and the search for the authentic self: the case of mood-modifying medicines. Soc.Sci.Med., 66(1), 170-181. Retrieved from PM:17905500

Szasz, T. (1960). The myth of mental illness. American Psycholgist, 15, 113-118.

Szasz, T. (1970). Ideology and Insanity; essays on the psychiatric dehumanization of man. New York: Anchor Books.

Szasz, T. (1996). The meaning of mind: language, morality and neuroscience. Westport, CT: Praeger.

Szasz, T. (2000). Mental disorders are not diseases. Retrieved from http://www.szasz.com/usatoday.html

Taylor, C. (1989). Sources of the Self; the making of the modern identity. Boston: Harvard University Press.

van Schaik, D. J., Klijn, A. F., van Hout, H. P., van Marwijk, H. W., Beekman, A. T., de Haan, M., \& van Dyck, R. (2004). Patients' preferences in the treatment of depressive disorder in primary care. Gen Hosp Psychiatry, 26(3), 184-189.

doi:10.1016/j.genhosppsych.2003.12.001

www.nhs.uk. (2018). Overview: Clinical depression. Retrieved from

https://www.nhs.uk/conditions/clinical-depression/ 